821.111(73).09-31

https://doi.org/10.18485/bells.2021.13.13

\author{
Aleksandra Vukotić \\ University of Belgrade \\ Faculty of Philology \\ Belgrade, Serbia
}

\title{
THE VALUE OF INNOCENCE IN TONI MORRISON'S GOD HELP THE CHILD
}

\begin{abstract}
The essay examines the value of innocence in Toni Morrison's God Help the Child with a focus on the representation of childhood. While innocence is generally considered to be inherent in little children, the essay shows that it is all but a fantasy for Morrison's youngest protagonists, who enter the world of adulthood prematurely as they are exposed to racial and sexual abuse. However, while Morrison's earlier works arguably framed the myth of the fall from innocence into experience as a fortunate fall into (self-)knowledge, and refashioned innocence as sin, in God Help the Child Morrison appears to have taken a more ambiguous approach. The powerful motif is inverted yet again, but this time Morrison challenges both the moral and the chronological paradigms of the fall as she examines the possibilities of moving in both directions, from innocence to experience and back.
\end{abstract}

Key words: Toni Morrison, God Help the Child, innocence, childhood, parenthood, trauma.

E-mail address: anjamaric@gmail.com; aleksandra.vukotic@fil.bg.ac.rs 


\section{Introduction}

An innocent, suffering child is a frequent focal point in Toni Morrison's oeuvre. In this sense, Morrison's last novel, God Help the Child (2015), seems almost like a tribute to her previous works, most explicitly The Bluest Eye (1970), her debut novel about the effects of toxic parenthood and childhood trauma, and Beloved (1987), her seminal novel which explores the unspeakable crime of infanticide, raising the question of the mother's guilt, among others. Commenting on the choice of narrative techniques and elements of magical realism, primarily in the character of Beloved, the ghost of the murdered child who comes back to haunt the living, Morrison explained that the (dead) girl was "the only one who could judge her mother. None of us could." (Oatman 2015). ${ }^{1}$ Indeed, the harrowing story about the woman who came to be known as "the modern Medea", ${ }^{2}$ a certain Margaret Garner, a $19^{\text {th }} \mathrm{c}$. African-American slave who killed her own daughter to save her from the same fate, makes little sense when it is pieced together from the court archives. Tony Morrison's novel, on the other hand, fleshes out the plight of both the slave mother and the killed daughter lost on historians. Similarly, The Bluest Eye also adopts a child's perspective in order to explore, as Toni Morrison explained in a 2007 foreword, "how something as grotesque as the demonization of an entire race could take root inside the most delicate member of society: a child; the most vulnerable member: a female" (qtd. in Hoby 2015). The perspective of a formerly silent - and silenced - young black girl ${ }^{3}$ reframes the historical account of racialized child rejection, abuse, and trauma, as it allows the author to juxtapose and re-evaluate the narratives of innocence, virtue and vulnerability on the one hand, with those of experience, corruption and the (im)possibility of resistance on the other.

To a certain extent, this part of Morrison's foreword to The Bluest Eye could apply to God Help the Child, which also addresses the suffering of abused children - notably, but not exclusively, young black girls - and their anger. Indeed, the original title for the novel was The Wrath of Children,

See also Morrison, 2019.

2 Refers to the painting "The Modern Medea" (Thomas Satterwhite Noble, 1867), which was based on Margaret Garner's story.

3 As Toni Morrison explains elsewhere, the silence was "enforced or chosen", as young black girls were "profoundly absent" not only from historical texts, but also from works of fiction (Morrison, 2019). 
preferred by Toni Morrison but dismissed by her editors (Chen 2016). According to Morrison, however, the book is precisely about children's wrath - "about what adults have done to them and how they tried to get through it and over it and around it and how it affected them" (Ibid.) - or, as we learn early in God Help the Child, "What you do to children matters. And they might never forget." (GHTC, 43). While the quote speaks about the possibility of endless perpetuation of childhood trauma, it also implies the inability of traumatized children to unburden themselves of such accumulated fury and frustration in their future life. In the novel we encounter a little girl called Rain, who was routinely coerced into sexual activity by her mother's clients, and who says she would "chop her [mother's] head off" were she to meet her again (GHTC, 102). Another girl imagines ripping her mother's blue-and-white wallpaper and returning her slaps (GHTC, 77). While expressions of fury may take different forms, the sheer abundance of such emotional outbursts supports Morrison's claim that children's wrath is one of the main themes in the novel. Thoughts of betrayal, humiliation and revenge gnaw at their hearts, as these children are prematurely ushered into the world of adulthood. However, since the persistence of unsettled grievances and resentment are closely connected to the abilities not commonly associated with children, principally (self-) awareness, knowledge and agency, the reluctance to include the theme of children's wrath in the title itself possibly reveals a degree of cultural resistance to this topic. The narrative of vulnerability, helplessness and innocence, reflected in the chosen title, appears to be more acceptable and attractive, however ironic the phrase.

Importantly enough, though, unlike in The Bluest Eye, the children in God Help the Child do not withdraw into Pecola's "perpetual innocence of insanity" (Otten 1989: 9) but leave the Edenic state of innocence by taking an early plunge into the experience of fury. In other words, the realm of experience, rather than that of innocence appears to be the natural habitat for Morrison's youngest protagonists in this novel. There are little girls and boys praying for beauty, recognition and love in the face of neglect, disregard and abuse. The level of violence awareness, however, differs as the youngest protagonists are alternately empowered and disempowered by their author, displaying a varying degree of self-regard, agency and rage.

For example, the protagonist in God Help the Child, one Lula Ann Bridewell, who reinvents herself as Bride, is yet another unloved daughter in Morrison's oeuvre whose childhood trauma leaves her unable to form 
meaningful and rewarding relationships in her adult life. Unfortunately, as we learn at the very beginning of the novel, her story of rejection due to her dark skin color seems to be paradigmatic of the experiences of the black community in the U.S., rather than an isolated example. Lula Ann's grandmother was also an unwanted child, abandoned by her mother because of her darker skin color, so that the mother would continue to enjoy "white privileges" - "Almost all mulatto types and quadroons did that back in the day" (GHTC, 4). Like her grandmother, Lula Ann was born to "high yellow" parents, and her misfortune started only a couple of hours after birth, when her skin rapidly changed from white to "[m]idnight black. Sudanese black" (GHTC, 3). Accusing his wife of infidelity, Lula Ann's father abandoned the family soon enough, leaving the mother to cope with the strange situation herself, stranger still given that the mother was white and the daughter black - "I could have been the babysitter if our colors were reversed" (GHTC, 6), the mother intimates, unwittingly revealing the enduring racist stereotypes still deeply rooted in modern society. The mother's response to the birth of her little black girl is hysterical. She even contemplates murder, "I know I went crazy for a minute because once just for a few seconds - I held a blanket over her face and pressed", and only moments later she has thoughts of giving her daughter "away to an orphanage someplace" (GHTC, 5). She is acutely aware that her daughter is bound to be doubly disenfranchised - based on both her race and sex, and that both her child and herself are likely to experience tremendous suffering in the process.

In order to detach herself from her own daughter and save some of the inherited "white privileges," she asks to be called "Sweetness' instead of 'Mother' or 'Mama"' (GHTC, 6), symbolically cancelling her role as a mother, though she continues to perform it in a toxic manner. Lula Ann grows up in a loveless environment, with a mother filled with disgust,

I always knew she didn't like touching me. I could tell. Distaste was all over her face when I was little and she had to bathe me. Rinse me, actually, after a halfhearted rub with a soapy washcloth. I used to pray she would slap my face or spank me just to feel her touch. (GHTC, 32)

Memories of a broken childhood, of neglect and abuse are scattered throughout the novel in the form of flashbacks, and it is not surprising that literary critics have mostly approached God Help the Child from the 
perspective of psychoanalysis and trauma studies. In a recently published monograph, New Critical Essays on Toni Morrison's God Help the Child: Race, Culture, and History, edited by Knox Eaton et al. (2020), half of the volume is dedicated to trauma and healing in the novel, which remain favorite topics among Morrison scholars. This paper, however, examines another important topic, or rather a theme, which appears to shape both the novel's story and discourse to a great extent - that of childhood innocence.

\section{Reframing innocence}

Loss of innocence is doubtlessly a common theme in American literature, and in the works of Toni Morrison it is typically linked with racial and sexual oppression. Interestingly enough, John N. Duvall has traced it back to The Sound and the Fury (1929), arguing that the theme of the "inevitable fall from childhood innocence into the knowledge of racial and sexual difference", which continues to be explored in postmodern and contemporary American literature, is primarily Faulknerian (Duvall 2008: 95). ${ }^{4}$ It is important to note that the "fall", as Duvall's argument goes, cannot be prevented - the children in these narratives are inevitably deprived of innocence, or childhood itself.

For Terry Otten, the myth of the fall from innocence into experience is a unifying theme in the works which Toni Morrison published in the 70's and 80's (he analyzes five novels - The Bluest Eye, Sula, Song of Solomon, Tar Baby and Beloved). In his study The Crime of Innocence in the Fiction of Toni Morrison (1989), Otten recognizes the author's ability to blend the racial and the universal, the African heritage and the Bible. Otten borrows the phrase "the crime of innocence" from Morrison's Tar Baby (1981), where one of the protagonists, Valerian Street, comes to a sudden realization that he is "guilty" of innocence, or rather of lack of knowledge, interest and ultimately of the courage to face the truth - his wife's abuse of their only son Michael. "Was there anything as loathsome as a willfully innocent man?

4 Duvall famously argued that the first black Nobel Laureate in America was not Toni Morrison but William Faulkner, in the sense that Faulkner, possibly unwittingly, deconstructed the southern stereotypes of blackness in his fiction (2008: x). Even though Morrison denied that Faulkner had had any impact on her work, she was a Faulkner scholar who close-read his writing as she did her MA thesis on Woolf's and Faulkner's treatment of alienation. 
Hardly. An innocent man is a sin before God." (TB, 217-218), he muses, inverting the Christian paradigm of innocence and experience. Otten notes that Morrison deconstructs the motif of the fall, creating worlds of moral ambiguity, with "gardens that oppress, sins that redeem", and argues that "[i]n all her novels the fall from innocence becomes a necessary gesture of freedom and a profound act of self-awareness." (Otten 1989: 3-5). It is rather clear that Otten's study interprets innocence as (self-)ignorance, and experience as knowledge and (self-)awareness, detecting in Morrison's early fiction elements of the romantic idea of a fortunate fall as the quest for the self. But Morrison's novels often explore the value of innocence in various stages of a person's development, including childhood, which complicates the idea of "innocence as guilt" and the fall into experience as a necessary and fortunate identity quest.

The meaning and value of innocence remain rather abstract and elusive, though. In a series of papers on the child figure ${ }^{5}$ and her book The Importance of Being Innocent: Why we worry about children (2011), Joanne Faulkner examines and re-evaluates the idea of childhood innocence. Faulkner starts with etymology, noting that "innocence' derives from the Latin innocere: "to do no harm"', and wonders about the power of such a negative definition in the Western imagination: "How could this negatively defined, insipid concept occupy such a prominent place in the hierarchy of value? And what must a culture have suffered or have feared suffering - what vulnerability must it feel - to so esteem the condition of doing no harm?" (Faulkner 2011: 7). In another study, she explains that the concept stems from the belief in the "natural innocence" of little children, which in turn arises from a "deficit of experience" (Faulkner 2013: 127-8; italics J.F.). What is more, as Joanne Faulkner elaborates, childhood innocence has come to be synonymous with childhood, and as such is often fetishized in Western society (2013: 128).

Toni Morrison's fiction, however, resists such presumptions of childhood innocence, primarily due to the stark contrast between what is considered a "typical", or "Western" perception of childhood, and the black experience. Whereas the privileged part of society attempts to shelter and "overprotect" the young, the underprivileged are ushered into the world

5 See, for example: Faulkner, Joanne. "The Innocence Fetish: The commodification and sexualisation of children in the media and popular culture" (2010: 106-17) and "Vulnerability of 'Virtual' Subjects: Childhood, Memory, and Crisis in the Cultural Value of Innocence." (2013: 127-147). 
of "experience" early in life - through poverty, child labor, racism, sexual abuse, etc. The young protagonists in Morrison's novels do not conform to the traditional discourses of childhood innocence for the very same reason, and as the paper will show, it hardly comes as "natural" for them in either sense of the term as a lack of experience, or "doing no harm."

In fact, the reader learns that the sufferings of little Lula Ann are not without consequences - or, as Jasmin Wilson has argued, she is "both victim and victimizer" (Wilson 2020: 30), in that she both endures abuse, and causes a significant amount of suffering in others. In order to get Sweetness to be "kind of motherlike" (GHTC, 32), Lula Ann wrongly accuses one Sofia Huxley, a twenty-year-old schoolteacher, of child molestation. While Lula Ann wins her mother's smile, and gets to hold her hand on this account (GHTC, 30-32), Sofia is given a twenty-five-to-life sentence, denounced by society as "the lady monster" (GHTC, 14), and abandoned by her own parents as "the filthy freak" (GHTC, 16). As she later remembers, "[i]n their world of God and Devil no innocent person is sentenced to prison." (GHTC, 68). Sofia, however, is unjustly sent to Decagon Women's Correctional Center, the prison which holds "evil women", the "sinful women committing bloody female crimes" (GHTC, 13), as it is sarcastically described by Morrison, whose vocal support of women's rights and deep distrust of the formal justice system was well-known. ${ }^{6}$

Indeed, the justice system in God Help the Child is deeply flawed, especially in its failure to protect the youngest and most vulnerable members of the population. While innocent Sofia is doing her time in Decagon, a real child predator, Mr. Humboldt, also known as "the nicest man in the world" (GHTC, 118) is at large, sexually abusing, maiming, and killing young boys in the neighborhood. He is not alone as we also encounter many others, such as Mr. Leigh, the landlord Lula Ann catches forcing himself on a young boy, and whom Sweetness refuses to report on, for fear of eviction. One character (Brooklyn) manages to escape her uncle's abuse, while yet another (Hannah) is unable to escape the sexual advances of her own father. Rain, the girl molested by her mother's customers, is rescued by a hippie couple, Evelyn and Steve, but Molly, a disabled daughter with "the loveliest blue eyes in the world" (GHTC, 67) is smothered by her mother Julie, Sofia's cellmate. Child abusers with and without names lurk

6 What we also learn in the novel is that the prison is primarily perceived as a private business, providing work for the locals, "Lucky for the state, crime does pay" (GHTC, 13). 
everywhere in the novel, and Mar Gallego has rightly noticed that "[t]he abundance of pedophilic episodes serves to highlight how contemporary society, far from protecting its young people, especially but not exclusively black girls and boys, exposes them to damage and corruption from a very early age." (Gallego 2020: 54). The reader reaches the conclusion early on that there is hardly anything "innate" about childhood innocence in God Help the Child. Toni Morrison reframes the discourse of childhood purity, representing corruption as "natural", and innocence as a site of longing.

\section{Corruption of innocence}

From the absence of touch and severe neglect to the touch of a pedophile, infanticide and murder, Morrison's novel explores the endemic corruption of innocence both literally and symbolically. On the one hand, stolen innocence is an important topic in a book populated with child molesters and abusers, but at the same time it is also a powerful symbol of the corruption of the innocence of a nation. The problems, however, begin on the level of the nuclear family, as Morrison clearly shows in her novel. As the author noted in an interview for Mother Jones, "Even when you think you've had a wonderful childhood, I suspect there's always some little drop of poison - that you can get rid of, but sometimes it just trails in the blood and it determines how you react to other people and how you think." (Oatman 2015). While the "drops of poison" in God Help the Child are by no means little, causing major childhood traumas, Lula Ann describes her problematic childhood and the corruption of innocence using precisely the same metaphor, "So I let the name-calling, the bullying travel like poison, like lethal viruses through my veins, with no antibiotic available." (GHTC, 57). There is no antibiotic for Lula Ann, and a number of other little black girls, we are to infer, simply because it has not been provided by the family and the community in general. On the contrary, Lula Ann learns from her parents - the absent father and the disinterested mother - that she is worthless, so obedience becomes her "only survival choice" (GHTC, 32). "And I was good at it. I behaved and behaved and behaved." (GHTC, 32), Lula Ann remembers, revealing the gradual but steady process of the internalization of the poisonous racist rhetoric and behavior. 
There are numerous other examples in the novel where Toni Morrison illustrates how racism plants its roots in children as the most fragile members of society. Scattered all over the novel are Sweetness's monologues in which she unwittingly explains the mechanism behind the corruption of innocence, primarily among young children:

I had to be strict, very strict. Lula Ann needed to learn how to behave, how to keep her head down and not to make trouble. I don't care how many times she changes her name. Her color is a cross she will always carry. But it's not my fault. It's not my fault. It's not. (GHTC, 7)

Or,

See if I hadn't trained Lula Ann properly she wouldn't have known to always cross the street and avoid white boys. But the lessons I taught her paid off because in the end she made me proud as a peacock. (GHTC, 41-42)

The two quotes reveal a series of processes through which a child is drawn into a downward spiral of low self-esteem, usually as the result of a very strict training routine. Unsurprisingly, the practice of teaching and acquiring self-hatred appears to be largely unconscious, as Sweetness is hardly aware of the effects of her "poisonous" behavior on her dutiful daughter. While she maintains that she is not to blame for giving birth to (yet another) black child - and almost apologizes for it (because Lula Ann will carry her "cross" forever) - Sweetness remains oblivious of her own role in her daughter's resulting traumas. To justify her parenting methods, Sweetness further explains that she had to withhold her love and tenderness in order to "protect" her daughter, who "didn't know the world", and prepare her for "a world where you could be sent to a juvenile lockup for talking back or fighting in school, a world where you'd be the last one hired and the first one fired" (GHTC, 41). In other words, Sweetness implies that the guilt she (sometimes) feels is shared, that it is communal rather than individual. Interestingly enough, the novel itself supports her point in more ways than one. From chapter to chapter, Morrison addresses the systematic and endemic nature of the corruption of the young through the sexist and racist language and behavior of the community. Thus, Mr. Leigh, the rapist, calls the six-year-old Lula Ann a "nigger cunt", words she had never heard before, "but the hate and revulsion in them didn't need 
definition", as the girl later remembers (GHTC, 55-56). Similarly, when in a parallel story in the novel a black boy called Adam goes missing one day, the police first search the parents' house and check if the father has a police record, then drop the search. In what appears to be a tribute to the "Black Lives Matter" movement, the narrator says ironically, "Another black boy gone. So?" (GHTC, 114). Adam's brothers and sisters learn that to the authorities their lives may not be as important as those of some other, more privileged children. Finally, Toni Morrison herself explained in an interview that, "unlovely as she is [...] there is truth in all of what Sweetness says", since "there is a hierarchy of good and bad and who gets to belong and have worth and who doesn't" (Chen 2016). Seen in this light, Sweetness's parental advice appears almost like a set of survival strategies.

Laying the blame elsewhere - on society, her ancestors, her husband, and the school-Sweetness opens and closes the novel with her self-justifying monologues. In fact, the novel begins with the words, "It's not my fault", and Sweetness will repeat this sentence ad nauseam in various formulations (as many as four times within the space of the first three pages). Despite maintaining her blamelessness, Sweetness can hardly be exonerated as she is clearly guilty of the "crime of innocence" as understood by Terry Otten. Hers is the case of the psychological mechanism of denial, which the reader will witness, to a certain extent, in almost all adult characters in the novel. As they give their testimonies one after another, they repeatedly try to justify their choices, unable to prevent the "little drop of poison" from spreading through their system, incapable of leaving the vicious circle of toxic behavior. In this sense we could safely say that the novel is also about the illusions of innocence - of particular characters, as well as of the whole nation. The novel, however, shows that awareness of guilt rather than insistence on blamelessness is the first step towards reclaiming both the personal and the national identity, and that the discourse of innocence can be rather limiting in this respect, though not always criminalized, as it will be argued in this essay. 


\section{From innocence to experience and back}

Equipped with no tools whatsoever for building a sense of self-esteem, Lula Ann needs to seek what Morrison famously termed the "source of selfregard" elsewhere - primarily in women's magazines, as the novel shows. Refusing to repeat the mistakes made by her fictional predecessor Pecola, Lula Ann decides to fight her childhood demons, and upon coming of age she reinvents - and redesigns herself. After changing her name from Lula Ann Bridewell to the memorable monosyllabic Bride, she hires a "total person designer" who teaches her to celebrate the color of her skin with mottos such as, "Black is the new black" and "Black sells" (GHTC, 36). To accentuate her blackness further, Bride is to wear only white clothes, and no makeup or jewelry, apart from the little pearl earrings. In short, the new fashion industry teaches her to love the skin her mother hated and dreaded, so that at the time the novel begins the sight of Bride makes people think of "Something classy. Bonbons. Hand-dipped", and she looks "like a panther in snow" to the excitement of men, who come to adore her (GHTC, 33, 36).

Fumbling through the world of experience, Bride embraces the hookup culture, enjoying casual encounters with random men, until she starts to "go steady" with one of them, Booker Starbern. When he leaves her after six months saying, "You not the woman I want", she is determined to find him and discover the reasons - not only for his decision, but also for her "sassy" answer, "Neither am I" (GHTC, 8). She embarks on a six-week-long journey, which proves to be a quest for self-discovery. The journey itself is filled with the most improbable episodes, which have been described by Morrison scholars alternately as elements of magical realism and Bride's hallucinations.

As soon as Bride sets off on her journey, her Jaguar crashes into "what must have been the world's first and biggest tree" (GHTC, 82), leaving her in the middle of the woods to be tended by a hippie couple, Steve and Evelyn, and their informally adopted daughter Rain, an unfortunate little girl of undetermined age and race. During her stay, Bride feels that her body is shrinking in size and that she is gradually reverting to a little girl, possibly Rain, whose jeans she gets to wear at one point. What is more, after breaking an ankle in a car accident, Bride is confined to bed, so Steve and Evelyn have to take care of her like a baby. The first in a series of inexplicable bodily transformations occurs immediately after Booker 
leaves her. As Bride is preparing to go to a party, she notices that her ears are no longer pierced. Instead, she now has "virgin earlobes [...] smooth as a baby's thumb" (GHTC, 51). Soon after discovering her altered earlobes, she notices the absence of her armpit and pubic hair. Around the same time, she feels that her body has shrunk from size 4 to size 2 , she notices that her chest is flat and that her menstrual periods have stopped. This is the point when Bride starts to believe that "the body changes began not simply after [Booker] left, but because he left" (GHTC, 94). She proves to be right in the end, to a certain extent. In a fairy-tale ending Bride learns that she is pregnant with Booker's child, which explains some of the bodily transformations, like the absence of menstruation:

A child. New life. Immune to evil or illness, protected from kidnap, beatings, rape, racism, insult, hurt, self-loathing, abandonment. Error-free. All goodness. Minus wrath.

So they believe. (GHTC, 175)

In short, in the end Bride and Booker are granted the opportunity to heal old wounds and renew their relationship - through a child - a symbol of purity and unconditional love which is the only possible answer to trauma in Morrison's oeuvre. ${ }^{7}$ In general, a child is typically perceived as "innocent of error and blame" (Faulkner 2013: 137), or "error-free" and "all goodness", in the words of Morrison's narrator, given that the child is nurtured in a safe environment which fosters healthy growth and feelings of confidence and security. Toni Morrison, however, makes sure to emphasize that this is only a fantasy as she closes the novel with Sweetness's sarcastic comment about "how the world is, how it works and how it changes when you are a parent" (GHTC, 178). Raising a child in the contemporary world is a serious challenge, and even more so if the child is black, or a girl, or both, in which case she is likely to experience "racism, insult, hurt, self-loathing", if not all of the above, possibly in her earliest youth. Among other issues, Morrison thoroughly questions the concept of childhood innocence through comments made by both the narrator and Sweetness: Does it come naturally or is it a construct? Whose childhood is immune to corruption and abuse? Can resistance be (un)built? Where does the childhood innocence narrative come from and what is its impact? What is its value?

7 See, for example, Wyatt 2017: 171-87. 
The novel makes it rather obvious that the innocence narrative excludes a large portion of the black community. As a black author, Toni Morrison is possibly arguing that a black child is everything but resistant to "evil or illness" and, contrary to the narrator's ironic remark, full of wrath. The novel itself can be understood as an outlet for the sound and the fury of the traumatized: it is no wonder the protagonists, Bride and Booker, shout, scream and hit each other toward the end of the novel (GHTC, 151-154).

Viewed in this light, childhood innocence can indeed be seen as a construct, as suggested by Joanne Faulkner (2013: 130), ${ }^{8}$ or a master narrative, as Toni Morrison might have defined it. In contemporary society it certainly is a fantasy for the vast majority of children who live in dire circumstances, and one whose origin should be explored in order to understand its meaning and impact. In this sense it may be worth noting that Morrison's fairy-tale narrative with elements of myth ${ }^{9}$ which analyzes the corruption of "all goodness" is in fact framed by the biblical story about the innocence and humility of little children. The novel opens with a New Testament epigraph about children, announcing one of the novel's main themes:

Suffer little children to come unto me, And forbid them not (Luke 18: 16)

Or, as rendered in the $4^{\text {th }}$ edition of The New Oxford Annotated Bible, New Revised Standard Version, "Let the little children come to me, and do not

8 Faulkner argues that " $\mathrm{t}]$ he rise of the figure of the innocent child as a premium marker of cultural value - and reification of adults' pasts - thus mirrors a growing uneasiness about cultural memory" (2013: 132).

9 The novel also lends itself to analysis according to the Jungian archetypes of child hero and child God, which share the central narrative of "miraculous birth and the adversities of early childhood." As Jung further explains, "The god is by nature wholly supernatural; the hero's nature is human but raised to the limit of the supernatural - he is 'semi-divine."' (Jung 1980: 165). The character of Lula Ann/Bride approaches these archetypes - for Sweetness the rapid change of her daughter's skin color at birth is inexplicable, almost supernatural, and Bride does not understand the transformation of her body until the very end of the novel. Furthermore, all the stories about suffering children in God Help the Child can be interpreted as a metaphor for the process of individuation, in line with Jung's argument that "the various 'child'-fates may be regarded as illustrating the kind of psychic events that occur in the entelechy or genesis of the 'self."' (Jung 1980: 166). 
stop them."10 Since the word "suffer", which here means "let", "allow", has assumed a wholly different meaning over the centuries, Morrison's epigraph sets a dismal tone to the novel. Indeed, God Help the Child is a novel populated by little children who endure agony because of severe neglect, rejection and racial and sexual abuse, while only few of them manage to heal their wounds and overcome their childhood trauma. The promise of the Kingdom of God, which according to the Bible belongs to children, seems far-fetched and unattainable for most of Morrison's characters. It is as early as in the opening chapter that we learn that the real world, unlike the Bible, operates with double standards, and that the underprivileged are likely to remain so. In an attempt to justify her choice to distance Lula Ann from herself, Sweetness tells her mother's story of two Bibles - strangely enough, on their wedding day, her mother and father "had to put their hands on the one reserved for Negroes". "The Bible! Can you beat it?" (GHTC, 4), Sweetness exclaims.

Furthermore, the epigraph also serves as a reminder of the general idea of children and childhood in The New Testament, as the reader may remember the continuation of Morrison's epigraph, which is of equal interest for this topic. Below are the two variations, from the Gospels of Luke, Mark and Matthew respectively:

Truly I tell you, whoever does not receive the kingdom of God as a little child will never enter it. (New Oxford Annotated Bible, Luke: 18: 17; Mark 10:15; my italics)

Or:

Truly I tell you, unless you change and become like children, you will never enter the kingdom of heaven. (New Oxford Annotated Bible, Matthew 18:3; my italics)

Even though Bible scholars agree that this excerpt from the gospels is "[n] ot an idealization of childhood", but that it "contrasts humility with selfrighteousness and self-satisfaction" (Coogan 2010: 1810, 1865), Christ's warning that one should take the position of the child, assume a child's perspective, or, according to Matthew, "change and become like children" in order to enter the kingdom of heaven is generally understood in the

10 All subsequent quotes from the New Testament will be given from the same edition of The New Oxford Annotated Bible. 
sense of opening and purifying one's mind and heart in order to achieve a state of innocence which comes naturally to children, as the story goes.

The message is, however, taken quite literally in the novel. In her quest for selfhood, Bride first has to become a little girl - both psychologically, and - as she believes - somatically, undergoing the already mentioned series of bodily transformations. ${ }^{11}$ The first occurs early on, when Bride is given a severe beating by Sofia Huxley on parole, leaving her with a swollen, disfigured face. This is probably the first instance of Bride's return to the "ugly" black girl with "the skin [her mother] hated" (GHTC, 32). Then come the inexplicable changes: the altered earlobes, loss of armpit and pubic hair, flat chest and the general shrinkage from a size 4 to a size 2. In fact, it is at the moment Bride notices her "virgin earlobes" (GHTC, 51) that she returns to the age of innocence, the time before she "testified against the Monster" (GHTC, 50) and wrongfully accused Sofia of child molestation. As a reward for her court performance, Sweetness has Lula Ann's ears pierced and buys her a pair of (fake) gold hoops. As already mentioned, the reverse bodily transformation from a woman to a little girl is completed when she breaks her ankle, which renders her immobile and vulnerable like a baby that needs to be taken care of. The accident itself bears a Biblical resonance - Bride's car crashes into "the world's first and biggest tree", which is a direct allusion to the Tree of the Knowledge of Good and Evil - a symbol of rebirth as well as that of original sin and loss of innocence. ${ }^{12}$

Approached from this angle, Toni Morrison's God Help the Child can be viewed as a novel about desired innocence. Bride's efforts to apologise to Sofia reveal precisely this longing for the age of innocence, the time before she gave false testimony against her teacher. Guilt-ridden, Bride plans her trip to Decagon Correctional Center for a whole year, saves the hefty sum

11 While Jean Wyatt claims that "Bride's transformation into the body of a little black girl (is) a corporeal representation of her temptation to remain the child victim of trauma" (Wyatt 2017: 184), Justine Tally argues that "it may not be "corporeal" at all in that Bride is the only one who notices the changes in her body" (Tally 2020: 133). Moreover, as Tally reminds us, Toni Morrison herself mentioned in an interview that Bride is returning "to that despised little black girl her mother didn't even like" "in her brain" (qtd. in Tally 2020: 133).

12 According to Joanne Faulkner, the biblical story about the loss of innocence "defines human being". As she explains in The Importance of Being Innocent, "In Western mythology, life begins innocent and wants to return to innocence, which thereby summarises all that is culturally valuable." (Faulkner 2011: 7). 
of five thousand dollars and buys a three-thousand-dollar Continental Airlines gift certificate, "all of which could take her anywhere. Comfort her, anyway;" (GHTC, 12). However, Sofia's violent response to Bride's attempt to make amends, and Booker's decision to leave her for forgiving someone he perceives as a pedophile, like the predator who murdered his brother, make Bride's efforts to regain some of the lost innocence all the more difficult.

The novel, however, shows that while it is impossible to retrieve childhood innocence, attempts can be made to build the coveted "immun[ity] to evil or illness" by striving for a higher state of innocence and purity of mind, or innocence with a difference. After all, as Toni Morrison concluded in one of her last interviews for The Guardian, "I just think goodness is more interesting" (Chen 2016). Goodness is also more demanding, as, according to Morrison, "[y]ou have to be an adult to consciously, deliberately be good - and that's complicated." (Ibid.). ${ }^{13}$ In this sense, Bride's return to childhood is not only physical and psychological, but also symbolic. When Booker tells Bride that she is "[n] ot the woman" he wants, and she clumsily answers "Neither am I", she may be implying that she is still the little Lula Ann, unable to take full responsibility for her own actions, but that she might feel ready to try to make substantial changes in her life, rather than merely cosmetic ones. In this sense, her journey is not only that of self-discovery, but also a quest for a different woman, the one she would rather be. It is clear from the novel, however, that the process of discovering a better self may begin only after all illusions of innocence and self-justification have been dismissed, such as "I wasn't the only witness" or "I was only eight years old" (GHTC, 30). It is only when Bride exclaims, "I lied! I lied! I lied! She was innocent. I helped convict her but she didn't do any of that." (GHTC, 153) that she possibly defeats her childhood demons. As she later muses, "Having confessed Lula Ann's sins she felt newly born. No longer forced to relive, no, outlive the disdain of her mother and the abandonment of her father" (GHTC, 162). Even though her childhood traumas are by no means healed, Bride's confession, through which she appears to be absolved from the "crime of innocence", marks the beginning of the recovery process.

13 Indeed, Jung pointed to the symbolic meaning of the archetypal narratives about suffering children, which "try to show how precarious is the psychic possibility of wholeness" and reveal "the enormous difficulties to be met in attaining this "highest good" (Jung 1980: 166). 
Like in her earlier novels, Morrison is careful to point to the potentially damaging and limiting effects of the discourse of (childhood) innocence. Even though Bride and Booker manage to renew their relationship once they have acknowledged their past mistakes and embraced humility and honesty, Booker's aunt Queen has her own doubts about the future of their relationship,

They will blow it, she thought. Each will cling to a sad little story of hurt and sorrow - some long-ago trouble and pain life dumped on their pure and innocent selves. And each one will rewrite that story forever, knowing the plot, guessing the theme, inventing its meaning and dismissing its origin. (GHTC, 158)

Queen's comments, just like those made by Sweetness, ironize the discourse of innocence, and prevent the novel from slipping into sentimentality. These two unlikeable but rather experienced women are not only saying that the idealization and oversentimentalization of one's childhood as the age of innocence have little basis in everyday black experience, but also that the innocence narrative is possibly confining, as it cancels agency and, as a result, a sense of responsibility. Neither Bride nor Booker are able to continue and possibly complete the process of individuation until they have acknowledged their past mistakes, as illusions of innocence perpetuate both the trauma and the accumulated anger.

\section{Conclusion}

It is probably no coincidence that Toni Morrison's first and last novel tackle the primordial image of the child, as "both beginning and end, an initial and a terminal creature" (Jung 1980: 178), and in God Help the Child, for the first time, there is a possibility that the suffering child will eventually come out triumphant. Indeed, as Morrison re-negotiates the cultural value of childhood innocence on the thematic, rhetorical and symbolic level of the novel, revealing its constructed and potentially limiting character, she invests her most vulnerable characters with power and agency. While the Bible underlines the humility of little children, Morrison's novel shifts the focus onto children's rage and resilience. In this novel about the abject neglect of the young and various forms of child abuse, systematically 
performed by their parents, mentors and the community as a whole, childhood innocence appears to be all but a fantasy product. Rather than suffering from a "deficit", Morrison's youngest characters are confronted with a certain surplus of experience, which they are ill-equipped to handle. Yet, the right question is not whether innocence is natural or sustainable (the novel clearly shows that it is not), but whether it should be pursued. Innocence is overvalued, Morrison's children seem to yell at the reader building immunity to corruption and abuse in earliest childhood appears to be a more important task.

\section{References}

Chen, A. (2016). Toni Morrison on Her Novels: 'I Think Goodness is More Interesting'. The Guardian, 4 Feb. 2016. Interview. (1 October 2020) $<$ www.theguardian.com/books/2016/feb/04/toni-morrison-godhelp-the-child-new-york>.

Coogan, M. D. (ed.) (2010). The New Oxford Annotated Bible, New Revised Standard Version ( $4^{\text {th }}$ edition). Oxford: Oxford UP.

Duvall, J. N. (2008). Race and White Identity in Southern Fiction: From Faulkner to Morrison. New York: Palgrave Macmillan.

Faulkner, J. (2010). The Innocence Fetish: The Commodification and Sexualisation of Children in the Media and Popular Culture. Media International Australia, 135, 106-117.

. (2011). The Importance of Being Innocent: Why We Worry about Children. Cambridge: Cambridge UP.

. (2013). Vulnerability of 'Virtual' Subjects: Childhood, Memory, and Crisis in the Cultural Value of Innocence. SubStance, Vol. 42, No. 3, Issue 132, 127-147. (10 December 2020) <www.jstor.org/ stable/24540728>.

Gallego, M. (2020). Childhood Traumas, Journeys, and Healing in Toni Morrison's God Help the Child. In: A. Knox Eaton et al. (eds.), New Critical Essays on Toni Morrison's God Help the Child: Race, Culture, and History, Jackson: The UP of Mississippi, 47-66.

Hoby, H. (2015). Toni Morrison: 'I'm Writing for Black People ... I Don't Have to Apologise.' The Guardian, 25 April 2015. Interview. (1 October 2020) $<$ www.theguardian.com/books/2015/apr/25/toni-morrison-booksinterview-god-help-the-child $>$. 
Jung, C. G. (1980).The Psychology of the Child Archetype. The Archetypes and the Collective Unconscious, $2^{\text {nd }}$ edition. Translated by R. F. C. Hull. Princeton: Princeton UP, 151-181.

Knox Eaton, A. et al. (eds.) (2020). New Critical Essays on Toni Morrison's God Help the Child: Race, Culture, and History. Jackson: The UP of Mississippi, 106-120.

Morrison, T. (2004). Tar Baby. Kindle. London: Vintage Books.

Morrison, T. (2015). God Help the Child. New York: Vintage.

Morrison, T. (2019). On Beloved. The Source of Self-Regard: Selected Essays, Speeches and Meditations. EPUB. New York: Alfred A. Knopf.

Oatman M. (2015). Toni Morrison Knows All About the 'Little Drop of Poison' in Your Childhood. Mother Jones, 21 April 2015. Interview. (1 October 2020) <www.motherjones.com/media/2015/04/tonimorrison-interview-god-help-the-child $>$.

Otten, T. (1989). The Crime of Innocence in the Fiction of Toni Morrison. Columbia: The University of Missouri Press.

Tally, J. (2020). Return of the Repressed: The Politics of Engraving and Erasure and the Quest for Selfhood in God Help the Child. In: A. Knox Eaton et al. (eds.), New Critical Essays on Toni Morrison's God Help the Child: Race, Culture, and History, Jackson: The UP of Mississippi, 123-139.

Wilson, J. (2020). Raising the Inner Child: Lessons of Emotional Development in Toni Morrison's God Help the Child. In: R. Fraser and N. King-Pedroso (eds.), Critical Responses about the Black Family in Toni Morrison's God Help the Child: Conflicts in Comradeship, London: Lexington Books, 29-44.

Wyatt, J. (2017). Love, Trauma, and the Body in God Help the Child. Love and Narrative Form in Toni Morrison's Later Novels. Athens: University of Georgia P, 171-187.

Received: 08 July 2021

Accepted for publication: 27 August 2021 